Europe's Journal of Psychology 2/2010, pp. 123-149

www.ejop.org

\title{
Counselling psychology and disability
}

\section{Pavlo Kanellakis}

South Staffordshire and Shropshire Healthcare NHS Foundation Trust, UK

\section{Abstract}

This article addresses disability-related theory and research associated to attitudes and social action, equality of opportunity, respect and inclusion. It highlights the significance of disability in counselling psychology and that counselling psychologists (as other such professionals) need to be mindful of the wider disability issues that may be related to even those clients who do not apparently present with disabilities. Issues of terminology and conceptualisation of the terms disability versus handicap are then addressed. Linking issues of equality of opportunity, inclusion \& respect to disability, as a psychosocial construct, leads to the exploration of individuals owning their own and their families' disabilities and, consequently, challenging the positioning of disability outside the personal. Counselling psychologists' approaches to working with disability are then discussed and four examples are explored. It is concluded that counselling psychologists can use their skills to intervene at preventative and organisational as well as psychological counselling/therapy level and that they are also contributing significantly as translators of medical jargon, mediators between clients and medical personnel, and as educators.

Keywords: counselling psychology, disability, social construct.

\section{Introduction}

Counselling Psychology's tradition is interlinked with the psycho-social construct of Disability. This article addresses some European dimensions of disability and uses the UK as an area for more in depth focus of the issues, since counselling psychology has been most established in this country. European legislation and subsequent national legislation are addressed in relation to practice and clinical examples are included. 
Furthermore, this article illustrates that counselling psychology work related to disability is characterised by diversity in terms of theoretical models, population groups, age span and work settings. It supports the importance of counselling psychologists learning from clients and the other professionals that work with them, rather than trying to ascribe to a specific model or technique. As disability is a concept that clusters together a diverse range of physical impairments, by focusing on the psychosocial impact of these impairments, this article also addresses disability-related theory and research associated to attitudes and social action, equality of opportunity, respect and inclusion.

\section{Historical background}

The discipline and profession of counselling psychology developed in the USA in the context of ex military personnel with disabilities, the needs of which the US Veterans Administration (VA) was established to meet. Patterson (1955), Cranston (1986) and Munley, Duncan, McDonnell, and Saver (2004) highlight the VA's significant contribution to the development of counselling psychology in the USA. Patterson draws particular attention to the Vocational Rehabilitation and Education program (inaugurated in 1943) that involved helping the vocational rehabilitation of hundreds of thousands of veterans with disabilities. Therefore, working with disabilities is part and parcel of the historical roots of counselling psychology rather than something alien to it.

Why consideration of disability is important to all counselling psychologists

All counselling psychologists are obliged to exercise professional practice in the context of legal and statutory obligations. Following earlier similar legislation in the USA (National Association of Councils on Developmental Disabilities, n.d.; Disabilities Rights Section of the U.S. Department of Justice, 2005), in the UK the Disability Discrimination Act 1995 and its 2005 amendment defines the obligations of all professionals with respect to disability, and this of course includes counselling psychologists, . An astonishing amount of the work of all counselling psychologists is covered under this legislation, which contradicts the idea that only some counselling psychologists work in the field of disability. Counselling psychologists need to be cautious not to ignore:

- mental health as well as physical disabilities (including specific learning disabilities such as dyslexia);

- disabilities with fluctuating or recurring (rather than sustained) symptoms; this 
includes disabilities with symptoms that are only noticeable when the person is under stress or tired (e.g. dyslexia) and disabilities with symptoms that are linked to seasons, times of day or night, lighting, temperature, humidity or other similar environmental factors (e.g. rheumatoid arthritis);

- disabilities that are disguised through avoidance of situations or through treatment or adaptations (such as counselling, hearing aid or prostheses);

- disabilities involving moderate impact on someone's ability to carry out day to day activities, such as shopping, reading and writing, having a conversation or using the telephone, watching television, getting washed and dressed, preparing and eating food, carrying out household tasks, walking and travelling by several forms of transport, and taking part in social activities (the threshold of substantial impairment is set to be when an individual cannot lift with one hand, for a reasonable period of time, a moderately heavy object such as a chair, briefcase, weekend bag and shopping bags; in terms of mobility, substantial impairment is considered to be when an individual cannot go up or down steps, stairs or gradients and cannot walk for a mile at more than a mere slow pace or without unsteady or jerky movements);

- minor adverse effects in several activities amounting to significant impairment;

- past disabilities;

- the people who are impacted by someone else's disability due to their relationship with them (e.g. family members);

- non-therapeutic but related work such as supervisory, training, research, managerial, marketing and collegial interactions.

Consider the following vignette about Ann:

Ann' is a 64-year-old client who avoids social situations and presents with mild symptoms of anxiety; the above symptoms seem to have started six months ago when they were moderate but Ann has been taking anxiolytic medication. Ann has been obese for a couple of years now (Body Mass Index of 30.5 places her at the lower end of the obese scale) and this might be linked to moderate back-pain which she had for two brief periods over the last two years. Ann avoids walking, especially in the summer, when she finds the sweating particularly uncomfortable; she uses lifts rather than staircases. Although it has not been tested, it is likely that she could not walk for a mile without an aid.

\footnotetext{
' All names have been changed; furthermore, material from different clients and colleagues has been amalgamated, so that the examples stated are as close as possible to my actual experience whist maintaining confidentiality
} 
Counselling psychologists might consider clients of theirs as not disabled, on the basis of their actual presentation and provide services to them without taking into account disability issues. This vignette firstly illustrates how, influenced by discriminatory attitudes linked to aging (United Nations World Health Assembly Committee B, 2005), we may feel tempted to discount the significance of the mobility problems of clients like Ann. The fact that Ann is not an unusual person is also characterised by the high prevalence of obesity in western countries; for example, according to Craig and Mindell (2008), in England approximately one in four (24\%) of the general adult population is obese. Similarly, we may be tempted to discount the significance of Ann's back pain, as it is a very common physical complaint and, in this case, has had a very sporadic presentation. Additionally, the recent nature of the anxiety symptoms may misleadingly indicate that they are of low significance.

Secondly, the Disability Discrimination Act legislation instructs professionals like counselling psychologists to consider whether a client is disabled based on their assessment of the hypothetical scenario that the client did not receive treatment for their presenting problems. In Ann's case, this includes the likelihood that both the psychological treatment and psychotropic medication are masking the severity of her symptoms. Therefore, Ann's hypothetical scenario is that if it is likely that the anxiety symptoms persisted for more than a year were she not to receive psychological treatment, then she would be covered by the Disability Discrimination Act even if she never had any accompanying physical impairments such as her obesity and back pain. It is also important to consider the likelihood that Ann's avoidance may not only contribute to the maintenance of her difficulties but also make her anxiety distress less visible.

Finally, it is important to note that because Ann's two episodes of back pain were spread over two years (i.e. more than one year), the back pain itself, which has an impairing effect on her mobility, would have been sufficient to cover her under the legislation. Similarly, the legislation would also cover her in relation to the summerspecific problems, as they have spread over two years.

Terminology

Davis and Gandy (1990) address the relationships between the terms disability, handicap, rehabilitation, habilitation and physical impairment. They link disability with psychological processes characteristic of people with impairments and handicaps. Having acknowledged that some people develop disabilities from early 
childhood or birth (and thus the term "habilitation" is used to highlight that in such cases there are no pre-developed physical, mental, social, vocational and economic functions to be restored), they conceptualise handicaps as the resulting functional limitations in a person's physical and social environment from medical impairments linked to long-lasting anatomic or functional abnormalities. Maki and Riggar (2004) emphasise the importance that the term handicap is only used for the sources of limitations, such as architectural features (i.e. buildings and roads being designed in ways that handicap people with various impairments) or negative social attitudes.

Bruyère, Van Looy and Peterson (2005) support the use of the new bio-psycho-social International Classification of Functioning, Disability and Health (ICF) of the World Health Organization. ICF uses the term disability for impairments, activity limitations and participation restrictions, whilst using the umbrella term of functioning for all body functions, activities and participation. Bruyère (2005) emphasises the benefits of universal adoption of such a conceptual system for rehabilitation service planning and delivery, counsellor education and research (e.g. using the same indicators of successful outcomes in the integration of persons with disabilities into the workforce and community for comparisons across service systems).

Disability as a psychosocial construct linked to equality of opportunity, inclusion and respect

The United Nations (1996) cite World Bank figures that put two thirds of all people with more than slight or mild disability in the poverty category.

In the European Union,

- compared to $64 \%$ of people without disabilities, approximately $38 \%$ of people with disabilities aged 16-34 across Europe have an earned income; two to three times more people with disabilities are unemployed compared to people without disabilities;

- people without disabilities are more than twice as likely to have reached third level education than people with disabilities;

- one in two persons with disabilities has never participated in leisure or sports activities;

- one third of people with disabilities has never travelled abroad or even participated in day-excursions due to inaccessible premises or services;

- compared to people without disabilities, more than twice the proportion of 
people with disabilities meet their friends and relatives less than once or twice per month (Eurostat, 2001 cited by the European Disability Forum, n.d.).

In the UK,

- disabled people are more than twice as likely as non-disabled people to have no qualifications (12\%as opposed to $30 \%$ );

- less than half of disabled people of working age are at work, compared with over 80 per cent of non-disabled people of working age;

- approximately half of people with disabilities are economically inactive compared with only $15 \%$ of the non-disabled population and

- households containing a disabled adult have a workless rate of over $30 \%$ compared with a rate of less than $10 \%$ for those households where no disabled adult is present, evidencing that disability has a great impact on the combined economic activity status of households too (Smith \& Twomey, 2002).

Counselling psychologists need to be aware of the extensive discrimination that people with disabilities face. Clients may not have such awareness and counselling psychologists' awareness of such social discrimination is of great importance, so that experiences are put into perspective. Also, Holzbaver and Berven (1996) acknowledge that differentiation of socio-economic power can lead to harassment of people with disabilities and it can be useful if harassment is named so, both in terms of the recipient of such harassment making sense of their experience and in terms of effective problem solving aiming to improve the situation.

Counselling psychologists can also make important contributions to the planning and evaluating of services, as well as practice and research. Therefore, familiarity with national demographic, economic, employment, health and other bio-psychosocial data sets is of great importance (Bruyère \& Houtenville, 2006).

People with disabilities face environmental impediments similar to those of other minorities (e.g. ethnic and racial ones) and a minority group status in the case of people with disabilities can lead to social action that decrease those environmental impediments, just as it has for many ethnic and racial minorities (Moore \& Feist-Price, 1999).

The disability status in racial, ethnic, gender or cultural minorities often results in multiple minority statuses, and compounded multiple negative effects of deprivation 
and denial of self-identification and preferred ways of life (Mpofu \& Conyers, 2004). For example, many lesbians and gay men with disabilities have been experiencing hopelessness because of belonging to several separate communities and rarely finding acceptance in any. Similarly, women with disabilities in general face a double handicap, being oppressed on the grounds of both being female and having disabilities (Palombi \& Matteson Mundt, 2005; Smith \& Twomey, 2002). Kanellakis (2000) similarly illustrates the case of gay people with disabilities linked to HIV/AIDS, who also face multiple discriminations. Morrow (2003) and Bowman (2003) address the case of lesbians, gay and bisexual people who also are from a racial or ethnic minority and have disabilities. On the other hand, counselling psychologists need to be aware that psychological skills and knowledge about accessing resources developed in relation to one minority status can develop into instrumental learning spreading into the other minority areas (Mpofu \& Harley, 2006).

Ignoring discrimination linked to disability impairs effective decision-making that takes into account all significant factors. Particular attention is needed to what individual counselling psychologists might not identify as linked to particular constructs as disability, but there might be grounds for others to conceptualise it in relation to disability. Such others include their colleagues and people with disability and those close to them, as well as the society in general, which is represented by various structures including legal and social care. Prendes-Lintel (2000) highlights the case of refugees, who "rarely understand the concept of ... disability ... or the complicated rules and regulations involved in health care delivery" (n.p.); this prevents them from adequately accessing social care and legal support linked to disability.

Bruyère, Erickson and VanLooy (2004) surveyed both U.S. and U.K. employers regarding their responses to respective legislation concerning accommodations or adjustments needed by applicants and employees with disabilities. They concluded that all health care professionals working with people with disabilities have a duty to understand employee rights and employer responsibilities under this legislation, they need to know where employers may have difficulty in responding to an accommodation request and be familiar with resources and processes that can support an effective response to such requests. Bruyère, Erickson and VanLooy (2006) also illustrated the research contributions of counselling psychologists to attitudes and practice of those involved in recruitment and management. Counselling psychology research has an important role in the efforts to ensure that the dominant societies are responsive and equitable in their economic and social 
policies and distribution of resources and services (Mpofu \& Conyers, 2004). After all, counselling psychology has a strong commitment to social justice and an affinity with critical psychology that goes beyond sophisticated critiques of the status quo (Prilleltensky \& Prilleltensky, 2003; Toporek, Gerstein, Fouad, Roysircar, \& Israel, 2005; Greene, 2005).

Feist-Price and Khanna (2003) emphasise the importance of professionals, such as counselling psychologists, to support and advocate for clients with disabilities to have reasonable adaptations made by employers to enable successful employment that comes with a plethora of bio-psycho-social benefits. In addition, Maki and Riggar (2004) highlight the commitment to supporting persons with disabilities in advocacy activities to enable them to further empower themselves.

Important aspects of empowerment and disempowerment are the restrictions on communicative representation. Mpofu and Conyers (2004) link the Foucault and Habermas' theories with social representation ones; they state that people (including professionals) without disabilities oppress the expression of people with disabilities and exercise their dominance through censorship. This, mostly unconscious, restriction of uncensored expression by people without disabilities often relates to what is said, and how, by people with disabilities about disabilities and themselves. According to this perspective, expressions of people with disabilities are judged and rejected by people without disabilities using criteria or norms that perceive people with disabilities as inferior. Only through conformity with the dominant discourse, and the ways in which it is expressed, are people with disabilities given access to high-impact means of communication. The professionalism of counselling psychology carries dangers concerning the appropriation of cultural information, disability-associated life stories and other related knowledge (Mpofu, Thomas, \& Thompson, 1998; Mpofu, 2000). The slogan "Nothing About Us Without Us" seems particularly poignant. In relation to the above, the positioning of the author of this article seems of great importance; I am a person with several (invisible) disabilities and I have several family members with a range of disabilities.

Owning one's own and one's families' disabilities: challenging the positioning of disability outside the personal experiences of counselling psychologists

Dr Apio is a black, female, counselling psychologist working for a cluster of schools in North London. She is 57 years old and currently single (she has had one significant relationship with a woman in the past). For the last 2 years she has been significantly 
impaired by back pain. She has mixed thoughts and feelings regarding her back pain as a disability. Her family-of-origin experiences were marked by women getting back pain from their mid fifties and there was a strong association with ageing.

She draws on her determination to not allow her physical pain to interfere with her work; she is trying very hard to keep a focus on what she can do rather than what she cannot do any longer. She needs more time to achieve some tasks, although the situation would have been worse if her knowledge and skills that she developed over the years did not compensate for the challenges she faces. Moreover, she is taking home a bit more work than she used to. In the evenings and the weekends she does not have time and energy to do as many of the pleasurable activities she used to, although she still does some.

Her work is a mix of clinical work, supervision, management and research on child psychology; the word disability does not appear in any of her research publications and, although it has been occasionally and fleetingly used in her clinical and management supervision sessions (both the ones she receives and the ones she provides), it has never been the focus. One of her therapy clients is 13-year-old Aliyah, a black student who has dyslexia, which was recently diagnosed by the other counselling psychologist who works for the school cluster. Aliyah also has mixed thoughts and feelings about her dyslexia; her family members and her friends question whether she would be ok if she were to try harder, rather than focus on external support.

Will Dr Apio address Aliyah's mixed thoughts and feelings about her dyslexia? Will her mixed feelings about her own back pain be a bridge for her to connect with Aliyah, or will the similarities prove overwhelming? Will Dr Apio parallel Aliyah's family and friends, by emphasising the development of determination (focus on intra-psychic processes) or will she emphasise interpersonal variables, linked to accessing support from others?

All people with impairments and associated handicaps, counselling psychologists included, are faced with the dilemma of whether to acknowledge or minimise the significance of their situation in relation to these; thus the issue of whether such counselling psychologists identify as having disabilities or not is highly linked to this personal dilemma. Moreover, it is important to acknowledge that, regardless of profession and presence or absence of disability, we all grow in a society that disempowers people with disabilities. 
Owen (1993), in an extended review of Guy's 1987 book "The Private Life of the Psychotherapist", highlights the link between counselling psychologists' own disabilities and Jung's notion of the shadow (i.e. what is hard to acknowledge and to tell others about). He debates the complexities of good enough therapy and the circumstances when therapists are not able to carry out their responsibilities sufficiently towards their clients in connection to disabilities.

The openness of counselling psychologists with disabilities about their disabilities challenges the negative stereotypes that people with disabilities have, just like the larger society, and provides positive role models for possible achievements and empowerment (Mpofu \& Conyers; 2002). This is in line with counselling psychology's emphasis on the therapeutic use of the self (Rowan \& Jacobs, 2002). On the other hand, we need to be cautious so that we avoid simplistic matching of clients with disabilities with counselling psychologists with disabilities. Similarly, caution needs to be shown when staff with disabilities receive attention in relation to their disability rather than as individuals. At the same time, the extent to which services mirror discrimination of people with disabilities (e.g. by under-representing them in their staffing on all levels of the hierarchies) is significant.

Tokenism theory (Mpofu \& Coneyers, 2002, citing data by Krogh, 1998), has been used to highlight:

- the perception that less consideration is given to the views of professionals with disabilities compared to their colleagues without disabilities (i.e. "contrast effects");

- the stereotypical view that people with disabilities should be recipients rather than makers of decisions (i.e. "role encapsulation");

- the contradiction that senior managers (who are rarely people with disabilities) on the one hand encourage their workers with disabilities to be self-managing, but on the other discourage from any initiatives that would reduce their dependency on the organisation in which they work (i.e. "ambivalence effects") and

- the pressure that professionals with disabilities feel to be unemotionally involved with their disability experience in the way that professionals without disabilities would, and to uncritically adopt management methods selected by higher levels of management (i.e. "assimilation effects").

The current challenge we face as a discipline and profession is how we match the challenges to avoid discrimination and the calls for social action with compassion and reconciliation that is inclusive of all rather than alienating. 
Counselling psychologists' approaches to working with disability

The only survey that focuses on counselling psychology and disability in its totality (rather than specific illnesses associated to disability) was conducted very recently (Kanellaki \& Kanellakis, 2009). All chartered psychologists whose details were included in the online Directory of Chartered Psychologists published by the British Psychological Society, and all the counselling psychologists who were members of the European Association of Counselling Psychology were invited to participate in this survey (the overwhelming majority of the members of the European Association of Counselling Psychology work or trained in the UK).

The responses of 98 participants who met certain criteria, which were developed through a process of data cleansing, were analysed quantitatively. A large percentage $(66 \%)$ of participants had worked, at least on a part-time basis, in private practice, whilst a significant number of participants had worked for the charity and voluntary sectors (31\%), although this seems like a small adjunct to their main work portfolio. A sizable percentage $(27 \%)$ had worked for the Employee Assistance Programmes, whilst the increased profile of counselling psychologists in public mental health hospitals or clinics is reflected by the $51 \%$ of respondents with such an experience. Forensic and social services employment were minimally represented.

The participants were characterised by having considerable professional experience; only $3.1 \%$ had training and experience of four years, whilst $22.7 \%$ had 11 15 years and 18.6\% 20-30 years. Maybe the less experienced counselling psychologists did not significantly relate to the topic, leading to their low participation; as counselling psychologists engage in the practice of counselling psychology, the issue of disability might be unavoidable and their learning might be increasing in the context of ongoing professional development. It might also be that prequalification counselling psychology training does not sufficiently sensitise newly qualified counselling psychologists to the issue of disability.

Although the research team drew attention to a number of research limitations and make suggestions for changes in future research in this area, a number of quantitative analysis findings were identified. The vast majority of the participants reported that they had been working with clients in the field of disability alongside other fields. They stated that the vast majority of their therapeutic work had been with people with disabilities on a one-to-one basis; there was a great range in how 
much this was in relation to the participants' overall work. Approximately half of the respondents reported that they had been working with carers of people with disabilities, although this seemed less when compared to direct work with people with a disability. Approximately a third of the respondents stated that they had been working on a one-to-one basis with professional and volunteer carers of people with disabilities, although this was again a small part of their overall work. Similarly, approximately a third of the participants reported that they had been working with families of people with disabilities, but again this was a small part of their overall work. Diversity seemed to be a theme, although one to one work was more predominant than group work.

Regarding the age groups of the counselling psychologists' clients with disabilities, only a small minority of the participants stated that they had not been working with working age adults. Actually, approximately a quarter of the respondents stated that they had only been working with this age group, and for half this was the dominant age group with which they had been working. Nevertheless, approximately a third of the participants had been working with older adults and the figure for teenagers was similar (although again, these client groups represented a small minority of the overall work of the respondents). In terms of school age children, approximately a quarter of the participants reported that they had been working with this age group (for the vast majority of the participants, this had been a third or less of their work). The work with pre-school age children was the smallest, both in terms of the percentage of the counselling psychologists with experience with this age group and in terms of this having been less than a third of their work).

The survey also investigated the theoretical models used by respondents in their work related to disability. More than half of the respondents reported that theyhad been using cognitive behavioural therapy. Approximately half of the respondents stated that they had been using a client-centred / humanistic model, whilst approximately a third of the participants reported that they had been using a psychoanalytic / psychodynamic model. Approximately a quarter of the respondents stated that they had been using a systemic approach and a similar percentage had been using an attachment-based approach. A very small minority had been using only one model, which is in line with the multi-model competencies of Counselling Psychologists in the UK. Nevertheless, counselling psychology is still debating about whether different models have more efficacy with different clients with disabilities, which mirrors the general ongoing debate about efficacy about psychological models. The debate includes whether some research evidence has greater weight than other pieces of 
research evidence, but the current situation is that we still need more research.

Examples of counselling psychology work

Example 1

In London, John, a 17-year-old man of Afro-Caribbean dissent, is referred to Dr Claus, a German counselling psychologist, for "challenging behaviour" and obesity. There are references to getting into fights and inappropriately touching girls of his age. John has been in contact with learning disabilities services since his education at a specialist school for children with cognitive impairment; his cognitive abilities had been paralleled to that of a child of five years of age. He has not been able to function on a day-to-day basis without significant support from specialist teachers and his family. Dr Claus discovers that John is the first of two children that his AfroCaribbean parents had, and when he was born this was a shock to both of them. His father had a distant relative with learning disability so this provoked guilt in him and some fear that he might be blamed for his first son's imperfection. His mother was a heavy smoker at the time and she also felt guilty and some fear that she would be blamed too. However, they have focused most of their energies and time looking after John. Consequently, they have been relating to John as if he were five years old. As John was growing up, his sexual behaviours have been met with fear, embarrassment, frustration and anger by his parents whilst his sexual feelings have been unattended. Three years ago, John's father died but he was excluded from the funeral, as his mother had strong feelings that "he would not really understand and ... get too upset"; John still keeps on asking his younger brother where their dad is. John's mental capacity to make decisions about what he wants in terms of relationships have been questioned and past psychometric assessments were referred to. However, Dr Claus has the sense that this was an underperformance linked to poor therapeutic alliance with the person who carried out the test administration; actually his IQ score has been presented as a figure with little reference to John as a person and the range of his abilities. During several sessions of getting to know John and his problems, Dr Claus is considering his input

- in relation to John and his family,

- a sexuality group that the counselling psychologist is co-facilitating with a speech and language therapist,

- a Gestalt group that the counselling psychologist is co-facilitating with an arttherapist,

- a therapy group that he co-facilitates with an occupational therapist and a 
dog-therapist (i.e. a dog which has been approved to work as a co-therapist),

- a cognitive-behavioural treatment in relation to the problems,

- mental capacity act assessment and advocacy and,

- psychometric re-assessment to address the hypothesised inaccuracies.

In work associated with learning disabilities frequent dilemmas are consent issues, who should be involved in the treatment and what the focus of the work should be. Each person might hold different opinions about these issues and, at times, it is not easy to establish how to bring them together, whilst not loosing either the individual or the systemic focus. The impact of discovering that their child has a learning disability on the parents cannot be underestimated (Woolfe \& Barrlett, 1996; Forster \& Tribe, 2005; Robins \& Kanellakis, 2008); this is often conceptualised by drawing on person-centred as well as psychodynamic (e.g. Fairbairn, Klein, Winnicott), attachment-based and developmental theories and research. Additionally, biological and physiological knowledge need to inform conceptualisations that guide interventions; in relation to the above vignette, people with the syndrome Prader-Willi tend toward obesity (Beitman et al., as cited in Forster \& Tribe, 2005). The strong feature of several other physical disabilities alongside learning disability makes multidisciplinary collaboration important.

Example 2

Ysberin is a white 71-year-old Welsh man who has been in a low-security inpatient unit for several years, as he is considered a threat to women (especially female children) and no alternative all-male accommodation can be found. He has two sons, one of which visits him regularly. The nursing staff have strong feelings for his sexual history but these are put to the side in order to physically nurse him as well as possible. The staff grade psychiatrist is wondering whether Ysberin has mild dementia.

Ysberin is referred for psychological input at his local NHS Psychological Services for Older Adults. This NHS Trust covers a large, thinly-populated, geographical area and the psychological services for older adults are split into sections. Psychological services in this specific locality are staffed by Dr Andre, a Maltese male counselling psychologist. The neighbouring section is not nearby and is staffed by a female clinical psychologist. Andre is considering his input in relation to (a) training staff in conceptualising the interplay between biological, social and psychological dimensions, (b) providing an experiential group for staff where they can process 
emotions rather than suppressing them until they become unmanageable and (c) working with the family system of Ysberin. Furthermore, as Dr Andre gets to know Ysberin, he realises that Ysberin needs a neuropsychological assessment regarding frontal lobe damage; Ysberin develops trust for Dr Andre and is open for Dr Andre to administer the tests. Dr Andre has recently administered such tests to another service user and received neuropsychological supervision by a senior colleague in the Trust.

The above illustrates not only the importance of not ignoring the needs of older clients with disabilities such as dementia but also the real life complexities of working with clients with neuropsychological problems (regardless their age) in thinly populated localities that are geographically spread out.

Although it is appreciated that not all UK counselling psychologists will want to develop expertise in the neuropsychological field, Fairfax (2007) links neuropsychological assessment with the phenomenological tradition of counselling psychology and presents the therapeutic relationship as an essential foundation of valid neuropsychological testing. Further to this, he also presents his positive experience of a UK pre-doctoral internship as a counselling psychologist in neuropsychology and he advocates for the expansion of such options in the UK.

A lot of counselling psychology attention has been on the neglected family members of people with head injuries, which can range from sensory motor disturbance to post-traumatic epilepsy, and to cognitive deficits such as impairment of learning and memory. Family members may experience threats of violence and be impacted by the various personality changes of people with brain injury. Jackson and Haverkamp (1991), drawing on the Lezak (1986) work, acknowledge that people with traumatic brain injury might have:

- impaired capacity for social perceptiveness, resulting in self-centred behaviour and reduced ability to be self-reflective and empathic;

- impaired capacity for self control, resulting in impulsivity, random restlessness and impatience;

- stimulus-bound behaviour, resulting in difficulties in organising and planning and decreased behavioural initiative;

- inability to profit from experiences, even when the ability to absorb new information is intact;

- other changes such as apathy, silliness, significantly increased sexual interest or decreased sexual inhibitions or virtual loss of sexual drive. 
All the above seem to have significant burden to the vast majority of the relatives, with severity levels reaching that of clinical diagnoses (e.g. depression or anxiety), as evidenced by a range of research findings. Furthermore, these are not restricted to care givers' family members.

On the other hand, systemic and interpersonal counselling psychology acknowledges the importance of interpersonal relationships to rehabilitation (e.g. in relation to family members' realistic or unrealistic optimism or pessimism, but also rigidity versus adaptive flexibility). It also acknowledges the benefit of developing communication and problem solving skills, as well as flexibility, in the way that families are psychologically structured (e.g. in terms of roles and responsibilities of each member). Such flexibility is important so that the family navigates through the complex challenges and dilemmas encountered.

It is important for counselling psychologists to pay attention to psychological processes of coming to terms with the news of the implications of a family member having a head injury. Initial shock, which is accompanied with denial of the longterm significance of demanding or childlike behaviours, might be followed by relief or thankfulness that at least imminent death has been avoided. However, when the realisation that the initial hopes for full recovery might not be realistic emerges, associated feelings of despair and mourning may be experienced before eventually managing to reorganise their family and individual lives and adapt, as well as possible, to the new circumstances. Systemic counselling psychology also focuses on communications of professionals who might use recovery language but actual refer to improvement and consequently might be confusing lay people.

Counselling psychology is also making positive contributions to the field through peer support groups for family members (Jackson \& Haverkamp, 1991) and psychoeducational group psychotherapy approaches for family members who are the primary caregivers of people with head-injured adults (Laver-Listhaus, 1991).

Example 3

Isla, a Scottish 55-year-old single mother, is seen with Paul, her 14 year old son, her main carer, by Dr Simon, a counselling psychologist who works in private practice, mostly as an Associate of various employee assistance programme companies (he also provides organisational consultancy and training on a contract basis). Dr Simon holds Level A and B Certificates in Occupational Testing with particular expertise in 
rehabilitation career counselling. During his counselling psychology training, he focused on cognitive behavioural therapy and family therapy. He has been recently trained in Eye Movement Desensitisation and Reprocessing (EMDR) and Interpersonal Psychotherapy (IPT). In the past, Dr Simon used to work for a Pain Management clinic.

Isla used to work as a Physiotherapy Assistant for the local hospital until two years ago when she was physically attacked by a hospital visitor and consequently lost mobility of her legs; moreover, she has been having severe back pain since the attack. Although she was diagnosed with PTSD for which she has not received treatment, one year ago, she went back to her job but she found that her work organisation was not making satisfactory accommodations for her and subsequently left.

Isla and Paul are having several arguments with each other. Paul states that he feels that he does not want to stop caring, that he is doing what is "right", that he is part of his mother, that he does not want to leave home as his mother might not manage without him and that now he would feel lost without his caring role. He adds that he feels different from other boys, that he often gets picked on at school and that his teachers do not really understand how tired he is. Although he implies that he feels trapped, that he does not see an end to the caring and that he feels envy for other children, he adds that he now accepts that this is how his life is. He confirms that he finds it hard to relax and that he is worried that he would be taken into care. Isla is pursuing compensation and Dr Simon is called as a witness to the court.

The above illustrate not only that such work might be interconnected with medicolegal work but also the complexities of working with professional or non-paid carers of people with disabilities. One in four Europeans has a family member with a disability (Eurostat, 2001 cited by the European Disability Forum, n.d.). In particular, Earley, Cushway and Cassidy (2007) highlight the needs of child carers of people with disabilities.

Hornby and Seligman (1991) emphasise the importance of consideration of the impact on the family; this is based on research findings, which support the view that "families are interdependent and that a disability in one member affects all family members, that is, no one is exempt from the effects of a disability in the family" (n.p.). Disability requires several thinking and behavioural shifts from the family. It is not only the individuals with the impairment but also their family members who have to make 
sense of what caused the disability, "why us" and what are the family implications of the disability in the future years. Family members might also share the larger society's negative views of people with disabilities and thus have to review those. In need of support, they might become affiliated to other families who are coping with similar situations, thus the families' friendships are affected too. On the behavioural domain, disability can mean a plethora of visits to hospitals, clinics and support groups. As many people with disabilities are cared for by other family members, there are many issues requiring behavioural management; examples include those linked to the hygiene, feeding or physical treatment at home, outpatient clinics or day hospitals (including transportation issues).

Hornby and Seligman (1991) and Papadopoulos (1995) emphasise that by definition (the significant negative impact of impairments to functioning), disability is associated with changing of family roles (e.g. breadwinners becoming supports at home or homemakers becoming breadwinners). Papadopoulos (1995) also acknowledges the research findings with a broad range of chronic illnesses in which good family relationships and practical and emotional support from the various family members have been associated with positive adjustments of the individuals with the disability. Progressive or terminal illnesses can provide the stimulus for families to come together and manage the challenges as well as possible confronted but chronicity can lead to families breaking down, especially in absence of support from wider social systems.

The Cognitive and Behavioural framework appears to be the dominant model in the field of pain and PTSD; it has been used flexibly and incorporated a range of techniques such as hypnosis to biofeedback (Winterowd, Beck, \& Gruener, 2003; Hetzel, 1999). Nevertheless, new methodologies such as EMDR and the role-transition focus of IPT seem particularly relevant too. Similarly, in the cases where the above approaches have not resulted in sustainable changes (as well as for clients with pronounced characterological difficulties) psychodynamic approaches within interpersonal and object-relationships frameworks are also useful.

Overall, the training and experiences as a counselling psychologist provide with a strong foundation for clinical work, training and research in the area of pain and symptom management, particularly drawing upon developmental themes, holistic approaches to health and wellness, the development of strengths and adaptive strategies, vocational training and commitment to diversity (Okey, 1998; Hetzel, 1999). 
Example 4

Counselling psychologists have also been making extensive contributions to HIV/AIDS work through research, (e.g. Bor, 1991), psychological therapy supervision (Bor , Scher, \& Salt, 1992b), vocational issues (Conyers, 2008), health concerns, diversity and social justice (Werth, Borges, McNally, Maguire, \& Britton, 2008). People with HIV/AIDS have experienced discrimination in general and also in work settings in specific; now that HIV is considered a chronic illness, people with HIV have been facing the challenges of starting or returning to work and keeping these jobs, as demonstrated in the following vignette (Bor \& Kanellakis, 2008)

Keith, a 4O-year-old white Englishman living in Manchester with Kayode, his 35 year old Zimbabwean partner are self-referred to Dr Mary, an English white counselling psychologist working in an HIV clinic; both Keith and Kayode are HIV positive. Dr Mary saw Kayode seven years ago, around the time that his then Afro-Caribbean partner called Jonathan was dying from an AIDS related illness. Kayode had found Dr Mary a supportive "outsider" from the gay communities overwhelmed with multiple losses and the Afro-Caribbean Christian community with strong anti-gay beliefs. Keith is under pressure to get a job as the original assumptions that he would be dead by now have changed with pharmacotherapy developments.

In this vignette, the current vocational rehabilitation focus is in contrast to the multiple bereavement theme that was previously particularly dominant in HIV counselling psychology work. Vocational themes are also significant when working with young people who were born with HIV who now cope with education and work as part of living with a chronic illness (Kanellakis 2000; Feist-Price \& Khanna, 2003). The above vignette also highlights the interplay of disability, culture, sexuality and religion linked to discrimination, and that counselling psychology work is also done with couples (Kanellakis 2000).

In relation to HIV, counselling psychologists have been addressing the education of professionals (Sherr \& Davey, 1991) and the wider society, as well as providing assessment and counselling to individuals, their loved ones, their caretakers (Gurney, 1995) and their communities (Bor, Miller, \& Goldman, 1992a; Bor \& Elford, 1998). Counselling psychologists have been making significant contributions to the education of professionals in informing clients who have been tested for HIV of their results and processing complex dilemmas connected to balancing the individual rights of clients with the rights of others. Decisions about disclosure of HIV status are 
not only linked to disclosure to social contacts, but also to which health professionals clients want to inform and from which health professionals involved in their care they wish to keep this information confidential. Counselling psychologists have also been addressing professionals' assumptions that clients always wish for a negative result, highlighting issues linked to clients wishing HIV infection / HIV positive diagnosis (Kanellakis 2000).

The above issues have been often associated with pre and post testing counselling (e.g. Bor, 1997). However, the complex work on disclosure is ongoing and involves not only adults but also children. For example, parents with HIV need to decide when to tell their children about their own status and HIV negative or positive parents are confronted with difficult decisions regarding when to inform their HIV infected children about their status.

Direct work has been done not only with individuals but also with families (Bor \& Elford, 1998) and groups affected by HIV/AIDS (Balmer, 1994). The most noticeable theoretical models used in this area are humanistic (Feist-Price \& Khanna, 2003; Gurney, 1995) and systemic (Bor et al., 1992a; Feist-Price \& Khanna, 2003) frameworks, although the importance of cognitions, as well as emotions, in relation to behaviours is recognised and cognitive behavioural techniques are also utilised, especially in terms of problem solving regarding the bio-psycho-social symptoms and the development of related skills (e.g. relaxation training; Bor \& Kanellakis, 2008). Particular attention has been paid to the psychological bases for beliefs underlying high-risk sexual behaviour (Sherr, Strong, \& Goldmeier, 1993).

Although the emphasis is often on post-testing counselling as the forum to explore support with dealing with a positive or negative diagnosis, including the complexities of telling others, the effectiveness of such counselling work significantly increases when psycho-education and exploration of the dilemmas has happened in pre-test counselling (Bor, 1993, 1997; Kanellakis, 2000). The contribution of counselling psychologists to the HIV field extends from pre-testing counselling to pre-medical intervention counselling (Bor, 1993). HIV and AIDS counselling entails not only complexities regarding neuropsychological functioning but also related decisions with significant ethical dilemmas such as that of suicide (Werth, 1993; Rogers \& Britton, 1994). 


\section{Conclusion}

Counselling psychologists can use their skills to intervene at preventative and organisational level, not only in terms of policy development but also developing and facilitating experiential groups that address attitudes towards disability (e.g. in schools; Triliva, Anagnostopoulou, Hatzinikolaou, \& Chimienti, 2009). Institutions (such as schools, hospitals, government organisations, etc.) and the professionals that staff them can be a source of not only support to families affected by disability but a source of stress for the family, as systems magnify not only positive impact but also negative too (e.g. through organisational discrimination) (Hornby \& Seligman, 1991). Counselling psychologists are making significant contributions, in terms of not only psychological counselling and therapy, but also as translators of medical jargon, as mediators between clients and medical personnel, and as educators.

\section{Acknowledgments}

The author would like to thank Professor Robert Bor, Cliff Robins, Barbara Douglas, Ray Woolfe, Jennefer D'Aubyn, Simon Cook and my clients for their contributions and support with this article.

\section{References}

Balmer, D.H. (1994). The efficacy of a scientific and ethnographic research design for evaluating AIDS group counselling. Counselling Psychology Quarterly, 7(4). [Online].

Bor, R. (1991). Efficacy of psychological therapies for people with HIV disease. AIDS Care, 3(4). [Online].

Bor, R. (1993). Efficacy of HIV counselling. Counselling Psychology Review, 8(2), 7-9.

Bor, R. (1997). Vancouver summaries: Disclosure. AIDS Care, 9(1), 49-53.

Bor, R., \& Elford, J. (1998). The family and HIV today: recent research and practice. London: Cassell.

Bor, R., \& Kanellakis, P. (2008). Telephone interview of R. Bor by P. Kanellakis on 23 April 2008 (50 minutes). [Recording in procession of the interviewer]. 
Bor, R., Miller, R., \& Goldman, E. (1992a). Theory and practice of HIV counselling: a systemic approach. London: Cassell.

Bor, R., Scher, I., \& Salt, H. (1992b). Supervising professionals involved in the psychological care of people infected with HIV/AIDS. Counselling Psychology Quarterly, 5(1). [Online].

Bowman, S.L. (2003). A call to action in lesbian, gay, and bisexual theory building and research. Counseling Psychologist, 31 (1), 63-69.

Bruyère, S.M. (2005). Using the International Classification of Functioning, Disability and Health (ICF) to promote employment and community integration in rehabilitation. Rehabilitation Education, 19(2-3), 105-117.

Bruyère, S.M., Erickson, W.A., \& VanLooy, S. (2004). Comparative study of workplace policy and practices contributing to disability nondiscrimination. Rehabilitation Psychology, 49(1), 28-38.

Bruyère, S.M., Erickson, W.A., \& VanLooy, S. (2006). The impact of business size on employer ADA response. Rehabilitation Counseling Bulletin, 49(4), 194-206.

Bruyère, S.M., \& Houtenville, A.J. (2006). Use of statistics from national data sources to inform rehabilitation program planning, evaluation, and advocacy. Rehabilitation Counseling Bulletin, 50(1), 46-58.

Bruyère, S.M., Van Looy, S.A., \& Peterson, D.B. (2005). The International Classification of Functioning, Disability and Health: contemporary literature overview. Rehabilitation Psychology, 50(2), 113-121.

Craig, R., \& Mindell, J. (2006). Health Survey for England 2006: Cardiovascular disease and risk factors. Leeds: The Information Centre.

Cranston, A. (1986). Psychology in the Veterans Administration: A storied history, a vital future. American Psychologist, 41 (9), 990-995.

Conyers, L.M. (2008). HIV/AIDS and employment research: A need for an integrative approach. Counseling Psychologist, 36(1), 108-117.

Davis M.E., \& Gandy G.L. (1990). Rehabilitation and disability: psychosocial case studies. Illinois, USA: Charles C. Thomas. 
Directgov. (n.d.). Age discrimination. Retrieved May 31, 2008, from: http://www.direct.gov.uk/en/Employment/Employees/DiscriminationAtWork/DG_100264 29.

Disability Discrimination Act (as modified by Schedule 8 thereof for application in Northern Ireland). (2008). Guidance on matters to be taken into account in determining questions relating to the definition of disability 2008: Elizabeth II. London: TSO (The Stationery Office).

Disability Discrimination Act. (2006). Guidance on matters to be taken into account in determining questions relating to the definition of disability 2006 (Revised): Elizabeth II. London: TSO (The Stationery Office).

Disabilities Rights Section of the U.S. Department of Justice. (2005). A Guide to Disability Rights Laws. Washington D.C.: author.

Earley, L., Cushway, D., \& Cassidy, T. (2007). Children's perceptions and experiences of care giving: A focus group study. Counselling Psychology Quarterly, 20(1), 69-80.

European Disability Forum (n.d.). About disability: Facts and figures about disability. Retrieved May 31, 2008, from: http://www.edffeph.org/Page_Generale.asp? ?DoclD=12534.

Fairfax, H. (2007). Testing times: Counselling psychology and the neuropsychological perspective. A personal view. Counselling Psychology Review, 22(4), 44-48.

Feist-Price, S., \& Khanna, N. (2003). School-to-work transition planning for school-aged children with HIV. Journal of Applied Rehabilitation Counseling, 34(1), 10-16.

Forster, P., \& Tribe, R. (2005). Professional and ethical issues when working with learning disabled clients. In R. Tribe \& J. Morrissey (Eds.), Handbook of Professional and Ethical Practice for Psychologists, Counsellors and Psychotherapists. Hove: Brunner-Routledge.

Greene, B. (2005). Psychology, diversity and social justice: Beyond heterosexism and across the cultural divide. Counselling Psychology Quarterly, 18(4), 295-306.

Gurney, S. (1995). Counselling the HIV 'affected' individual: a case study. Counselling Psychology Quarterly, 8(1), 17-25.

Hetzel, R. (1999). A day in the life of a Counseling Health Psychologist: pain and symptom 
management. Counseling for Health, 24, 7-12.

Holzbaver, J.J., \& Berven, N.L. (1996). Disability harassment: A new term for a longstanding problem. Journal of Counseling and Development: JCD, 74(5), 478-483.

Hornby, G., \& Seligman, M. (1991). Disability and the family: Current status and future developments. Counselling Psychology Quarterly, 4(4). [Online].

Jackson, A., \& Haverkamp, B.E. (1991). Family response to traumatic brain injury. Counselling Psychology Quarterly, 4(4). [Online].

Kanellaki, A., \& Kanellakis P. (2009). Counselling Psychologists and Disability. The European Journal of Counselling Psychology, 1, 38-76. [Online].

Kanellakis, P. (2000). Issues in HIV/AIDS counselling. In C. Neal \& D. Davies (Eds.), Issues in therapy with lesbian, gay, bisexual and transgender clients. Buckingham: Open University Press.

Laver-Listhaus, B. (1991). Group psychotherapy for families of head injured adults: A psychoeducational approach. Counselling Psychology Quarterly, 4(4). [Online].

Maki, D.R., \& Riggar, T.F. (2004). Concepts and Paradigms. In T.F. Riggar \& D.R. Maki (Eds.), Handbook of Rehabilitation Counseling. New York: Springer Publishing Company.

Moore, C.L., \& Feist-Price, S. (1999). Societal attitudes and the Civil Rights of persons with disabilities. Journal of Applied Rehabilitation Counseling, 30(2), 19-24.

Morrow, S.L. (2003). Can the master's tools ever dismantle the master's house? Answering silences with alternative paradigms and methods. Counseling Psychologist, 31 (1), 70-77.

Mpofu, E. (2000). Rehabilitation counselling: issues in professionalization and identity. Rehabilitation Education, 14(2), 199-205.

Mpofu, E., \& Conyers, L.M. (2002). Application of tokenism theory to quality enhancement in rehabilitation services. Journal of Applied Rehabilitation Counseling, 33(2), 31-37.

Mpofu, E., \& Conyers, L.M. (2004). A Representational Theory Perspective of Minority Status and People with Disabilities: Implications for Rehabilitation Education and Practice. Rehabilitation Counseling Bulletin, 47(3), 142-151. 
Mpofu, E., \& Harley, D.A. (2006). Racial and Disability Identity: Implications for Career Counseling for African Americans With Disabilities. Rehabilitation Counseling Bulletin, 50(1), 14-23.

Mpofu, E., Thomas, K.R., \& Thompson, D. (1998). Cultural appropriation and rehabilitation counseling: implications for rehabilitation education. Rehabilitation Education, 12(3), 205-216.

Munley, P.H., Duncan, L.E., McDonnell, K.A., \& Saver, E.M. (2004). Counseling psychology in the United States of America. Counselling Psychology Quarterly, 17(3), 247-271.

National Association of Councils on Developmental Disabilities. (n.d.). Developmental Disabilities Act History. Retrieved May 31, 2008, from: www.nacdd.org/course2/history/DDActHistory.doc.

Okey, J.L. (1998). Pain management. In S. Roth-Roemer, S.R. Kurpius \& C. Carmin (Eds.), The emerging role of counseling psychology in health care. New York: W.W. Norton.

Owen, I. (1993). On 'The Private Life of the Psychotherapist' and the psychology of caring. Counselling Psychology Quarterly, 6(3), 251. [Online].

Palombi, B.J., \& Matteson Mundt A. (2005). Achieving Social Justice for College Women With Disabilities. In R. Toporek, L. Gerstein, N. Fouad, G. Roysircar \& T. Israel (Eds.), Handbook for Social Justice in Counseling Psychology: Leadership, Vision, and Action. Thousand Oaks, USA: Sage Publications.

Papadopoulos, L. (1995). The impact of illness on the family and the family's impact on illness. Counselling Psychology Quarterly, 8(1), 27-34.

Patterson, C.H. (1955). The role of counseling psychology in rehabilitation: Comment. Journal of Counseling Psychology, 2(2), 154-155.

Prendes-Lintel, (2000). Health Needs of Refugees: A Counseling Health Psychologist's Role. Counseling for Health. [Online]. Retrieved May 31, 2008 from: http://counseling.indstate.edu/hlthpsy/news/no26.htm.

Prilleltensky, I., \& Prilleltensky O. (2003). Synergies for wellness and liberation in counseling psychology. Counseling Psychologist, 31 (3), 273-281.

Robins, C., \& Kanellakis, P. (2008). Face-to-face interview of C. Robins by P. Kanellakis on 
28 April 2008 (90 minutes). [Recording in procession of the interviewer]

Rogers, J., \& Britton, P.J. (1994). AIDS and rational suicide: A counseling psychology perspective or a slide on a slippery slope. Counseling Psychologist, 22(1), 171-178.

Rowan, J., \& Jacobs, M. (2002). The therapist's use of self. Buckingham, UK: Open University Press.

Sherr, L., \& Davey, T. (1991). Counselling implications of anxiety and depression in AIDS and HIV infection: A pilot study. Counselling Psychology Quarterly, 4(1). [Online].

Sherr, L., Strong, C., \& Goldmeier, D. (1993). Sexual behaviour, condom use and prediction in attenders at sexually transmitted disease clinics: Implications for counselling. Counselling Psychology Quarterly, 3(4), 343-352.

Smith, A., \& Twomey, B. (2002). Labour market experience of people with disabilities. Labour Market Trends, 110 (8), 415-427.

Toporek, R, Gerstein, L, Fouad, N, Roysircar, G., \& Israel, T. (2005). Handbook for Social Justice in Counseling Psychology: Leadership, Vision, and Action. Thousand Oaks, USA: Sage Publications.

Triliva, S., Anagnostopoulou, T., Hatzinikolaou, S., \& Chimienti, G. (2009). The development and evaluation of a programme to sensitize Greek Grammar School Students to issues relating to disability. European Journal of Counselling Psychology, 1, 3-17. [Online].

United Nations. (1996). Focus on Poverty and Disability. New York: United Nations Department of Public Information.

United Nations World Health Assembly Committee B. (2005). Disability, including prevention, management and rehabilitation. Ninth plenary meeting, third report (pp. 108-111). United Nations.

Werth, J.L. (1993). Recommendations for the inclusion of training about persons with HIV disease in counseling psychology graduate programs. Counseling Psychologist, 21 (4), 668-686.

Werth J.L., Borges, N.J, McNally, C.J., Maguire, C.P., \& Britton, P.J. (2008). The intersections of work, health, diversity, and social justice: Helping people living with HIV disease. Counseling Psychologist, 36(1), 16-41. 
Winterowd, C., Beck, A.T., \& Gruener, D. (2003) Cognitive Therapy with Chronic Pain Patients. New York: Springer Publishing Company, Inc.

Woolfe, R., \& Barrlett, S. (1996). One bad experience is one too many: Parents' experience of the diagnosis of disability in their infants. Counselling Psychology Review, $11,7-11$.

About the author:

Pavlo Kanellakis works as a Consultant Psychologist in the NHS and KCA UK and is a member of a number of educational boards and faculties in the field of psychology, counselling and psychotherapy (e.g. Efficacy \& Mechanism Evaluation College of Experts of the Medical Research Council / National Institute for Health Research Evaluation, Trials \& Studies Coordinating Centre). He is a Health Professions Council UK registered counselling psychologist and British Psychological Society Chartered Psychologist, as well as registered Psychologist Specialising in Psychotherapy with Senior Practitioner Status. He is also the Editor of the free and open-access European Journal of Counselling Psychology.

Corresponding details: 117 Gainsborough Road, Hayes UB4 8QG, UK. 